\title{
A Survey of the In Vitro Antifungal Activity of Heather (Erica Sp.) Organic Honey
}

\author{
Xesús Feás ${ }^{1}$ and María L. Estevinho ${ }^{2}$ \\ ${ }^{1}$ Department of Anatomy and Animal Production, Faculty of Veterinary Science, \\ University of Santiago de Compostela, Lugo, Galicia, Spain. \\ ${ }^{2}$ Mountain Research Center, Agricultural College of Bragança, Polytechnic Institute of Bragança, Bragança, Portugal.
}

\begin{abstract}
Monofloral heather (Erica sp.) honey samples $(n=89)$, harvested in Portugal according to European organic beekeeping rules, were analyzed to test their antifungal effect against Candida albicans, Candida krusei, and Cryptococcus neoformans. A synthetic honey solution was also tested to determine antifungal activity attributable to sugars. The specific growth rate $(\mu)$ values showed that growth of all the yeasts was reduced in the presence of honey. The honey concentration $(\%$ $\mathrm{wt} / \mathrm{vol})$ that inhibited $10 \%$ of the yeast growth $\left(X_{\min }\right)$ was $13.5 \%$ for C. albicans, $20.5 \%$ for $C$. krusei, and $17.1 \%$ for $C$. neoformans. The respective concentrations of heather honey and synthetic honey in the $C$. krusei culture medium above $60 \%$ (wt/vol) that inhibited $90 \%$ of the yeast growth $\left(X_{\max }\right)$ and $X_{\min }$, respectively, were established, whereas C. albicans and $C$. neoformans were more resistant because $X_{\max }$ values were not reached over the range tested (10-60\%, wt/vol). Heather honey might be tapped as a natural resource to look for new medicines for the treatment of mycotic infections. Further studies are now required to demonstrate if this antifungal activity has any clinical application.
\end{abstract}

KEY WORDS: • antifungal effects • Candida albicans • Candida krusei $\bullet$ Cryptococcus neoformans $\bullet$ Erica species - honey

\section{INTRODUCTION}

$\mathbf{T}$ HE FACT THAT HippocRATES, the father of medicine, emphasized the pharmaceutical value of honey is not accidental. When analyzing and studying the therapeutic properties of honeys, modern science has made it possible to specify their medical significance as bactericidal, bacteriostatic, antiviral, antioxidant, anti-inflammatory, and antitumoral. ${ }^{1-3}$ Very few attempts have been made to date to assess the antifungal properties of honey ${ }^{4-8}$ if we compare these findings with the large volume of published literature that has established that honey has significant antibacterial activity.

Although all honeys have a common composition with a high sugar content, low moisture, and acidity that prevents microbial growth, ancient physicians were selective as to which honeys they included in their remedies. In fact, in the last decade, research indicates that honey quality and health properties depend largely on the floral source, ${ }^{9}$ together with other factors such as climatic conditions, soil type, and beekeeper activities. ${ }^{10}$ In any case, concerns about traces of numerous toxic substances have brought about a certain demand for honey that is certified as being organic. ${ }^{11}$

Manuscript received 15 August 2010. Revision accepted 17 March 2011.

Address correspondence to: Xesús Feás, Ph.D., Department of Anatomy and Animal Production, Faculty of Veterinary Science, University of Santiago de Compostela, E-27002, Lugo, Galicia, Spain, E-mail: xesusfeas@gmail.com
Organic honeys are produced using strict ecological and natural principles that are meant to enhance the good quality of the honey harvested, and they are free from many problems associated with honey from other parts of the world, such as pollution fallout and chemical residues. ${ }^{12}$ Honeys to be used for therapeutic purposes should be harvested in areas with no contamination sources.

The incidence of fungal infections is increasing in community and hospital environments, ${ }^{13}$ and no other mycotic pathogen produces a spectrum of opportunistic diseases in humans and animals as Candida does. ${ }^{14,15}$ Furthermore, the rate of candidemia caused by non-Candida albicans species is increasing, and among these candidiasis-causing agents, Candida krusei, which is an opportunistic pathogen isolated in some medical centers, can cause serious infections in susceptible patients. ${ }^{16}$ Those infections are difficult to treat owing to their reduced susceptibility to common antifungal agents. Another important encapsulated yeast-like fungus is Cryptococcus neoformans, responsible for infectious diseases in patients with AIDS. ${ }^{17}$ As far as we know, there are no studies that report on the action of honey against C. neoformans and C. krusei.

The detailed characterization of the different honey types existent in Portugal is important because this country is recognized as having nine protected "denomination of origin" regions for honey, from a total of 18 in the European Union. ${ }^{18}$ Heather honey is characterized by its dark brown color, strong flavor, and a slightly salty taste, which is 
produced in Portugal from Erica sp., whereas in Spain and France it comes from either the Calluna or Erica sp. The Ericaceae family is often used in folk medicine as an alternative therapeutic tool to treat hyperlipidemia, as a diuretic, astringent, or antiseptic, and in the treatment of urinary infections. ${ }^{19-21}$

The aim of this short publication is to assess the in vitro antifungal properties of Portuguese organic heather (Erica sp.) honey against C. albicans, C. krusei, and C. neoformans.

\section{MATERIALS AND METHODS}

\section{Heather honey}

Honeys $(n=89)$ were collected in 2008 from various beekeeping organic explorations in the North of Portugal. Even though the beekeepers themselves, according to the best of their knowledge and the location of hives, declared their honey as monofloral heather honey, all the samples were subjected to pollen analysis by the Erdtman acetolysis method; these are described in detail in a previous publication. $^{22}$ Results from the quantitative pollen analysis showed that the samples analyzed always had Erica sp. as the predominant pollen (at least $45 \%$ ). Amount per sample varied between $59 \%$ and $72 \%$, with the mean value being $69 \%$ and having an SD of 4\%. Pollen grains of Lavandulla sp., Prunus sp., and Echium sp. were found in all honey samples $(100 \%)$ with mean values of $14 \%, 11 \%$, and $6 \%$, respectively.

\section{Control}

A synthetic honey solution with a carbohydrate composition similar to that of natural honey was used to determine whether inhibitory effects were due to the sugar content of the honey samples: $100 \mathrm{~g}$ was prepared by dissolving $1.5 \mathrm{~g}$ of sucrose, $7.5 \mathrm{~g}$ of maltose, $40.5 \mathrm{~g}$ of D-fructose, and $33.5 \mathrm{~g}$ of D-glucose in $17 \mathrm{~mL}$ of sterile, deionized water. This highly viscous solution was kept refrigerated at $4^{\circ} \mathrm{C}$ when not in use.

\section{Microorganisms and culture conditions}

Microorganisms labeled CECT were obtained from the Spanish Type Culture Collection of Valencia University, Valencia, Spain, whereas microorganisms labeled ESA were strains clinically isolated in the Centro Hospitalario do Nordeste E.P.E. of Bragança, Portugal, and identified in the Microbiology Laboratory of the Polytechnic Institute of Bragança. The fungal strains used were C. albicans (CECT 1394), C. krusei (ESA 11), and C. neoformans (ESA 3). Microorganisms were cultured aerobically at $30^{\circ} \mathrm{C}$ on sterile yeast peptone dextrose medium containing $2 \%$ (w/vol) glucose, $1 \%(\mathrm{w} / \mathrm{vol})$ peptone, $1.5 \%$ (w/vol) agar, and $0.5 \%$ (w/vol) yeast extract. Before experimental use, cultures from solid medium were subcultured in liquid medium, incubated, and used as the source of inocula for each experiment.

\section{Test assays for antifungal activity}

Before the test assays for antifungal activity, the honey samples were pasteurized according to the technique of Becker et al. ${ }^{23}$ Erlenmeyer flasks $(150 \mathrm{~mL})$ with $50 \mathrm{~mL}$ of yeast peptone dextrose medium were inoculated with the yeast suspension $\left(10^{8}\right.$ colony-forming units $\left./ \mathrm{mL}\right)$, and each concentration of honey over a range of $0 \%$ to $60 \%(\mathrm{wt} / \mathrm{vol})$ to be tested was added. Incubation was carried out for 2 days at $37^{\circ} \mathrm{C}$ in a rotary shaker at $150 \mathrm{rpm}$.

The specific growth rate $(\mu)$ values of yeast cultures were monitored by measuring optical density at $640 \mathrm{~nm}$ in a ultraviolet-visible spectrophotometer and were calculated by least-squares fitting to the linear part of the semilog growth plot. The concentration that inhibited $10 \%$ of yeast growth $\left(X_{\min }\right)$ and the concentration that inhibited $90 \%$ of yeast growth $\left(X_{\max }\right)$ were determined by linear regression analysis. A more detailed presentation of this method has been previously reported. ${ }^{24}$

In the analysis involving synthetic honey, the same methodology was followed, replacing the heather honey by the same concentrations of synthetic honey and treating as described above. All heather and synthetic honey samples were analyzed during the same time period by three different analysts to ensure uniform conditions and comparability.

\section{RESULTS AND DISCUSSION}

Different concentrations of heather honey (10-60\%) were screened for their antifungal activity against $C$. albicans, $C$. neoformans, and C. krusei. A synthetic honey solution was also tested to determine activity attributable to sugars. The $\mu$ for fungi was determined, and results are presented in Figure 1. The results showed that the increase of heather honey concentrations caused a decrease in $\mu$ for all organisms studied. The $X_{\min }$ and $X_{\max }$ were determined by linear regression analysis and are shown in Table $1 . X_{\min }$ values ranged from $20.5 \%$ for $C$. albicans to $13.5 \%$ for $C$. krusei to $17.1 \%$ for $C$. neoformans, with $C$. krusei being the most susceptible to honey because growth inhibition is reached at the minimum level. Moreover, according to the $X_{\max }$ obtained, $C$. krusei was the most susceptible to negative effects of the tested solutions. The presence of heather honey in the C. krusei culture medium at concentrations above $60 \%$ (wt/ vol) inhibited $90 \%$ of the yeast growth $\left(X_{\max }\right)$. In contrast, the same concentration of synthetic honey was established as $X_{\min }$ for $C$. krusei, whereas $C$. albicans and $C$. neoformans were more resistant. More important is that this is the first report testing the in vitro antifungal potential of honey against $C$. krusei. Antifungal activity against $C$. krusei, in particular, is noteworthy given the acquired and intrinsic resistance of this species to fluconazole. ${ }^{16}$

Our data suggest that the honey mechanism for fungal growth inhibition is not related to the osmotic shock derived from the presence of sugar in the culture medium. In the same way, previous reports have demonstrated that increased honey concentrations resulted in reduced growth of C. albicans, namely, $29.4 \%$ inhibition of the growth was 

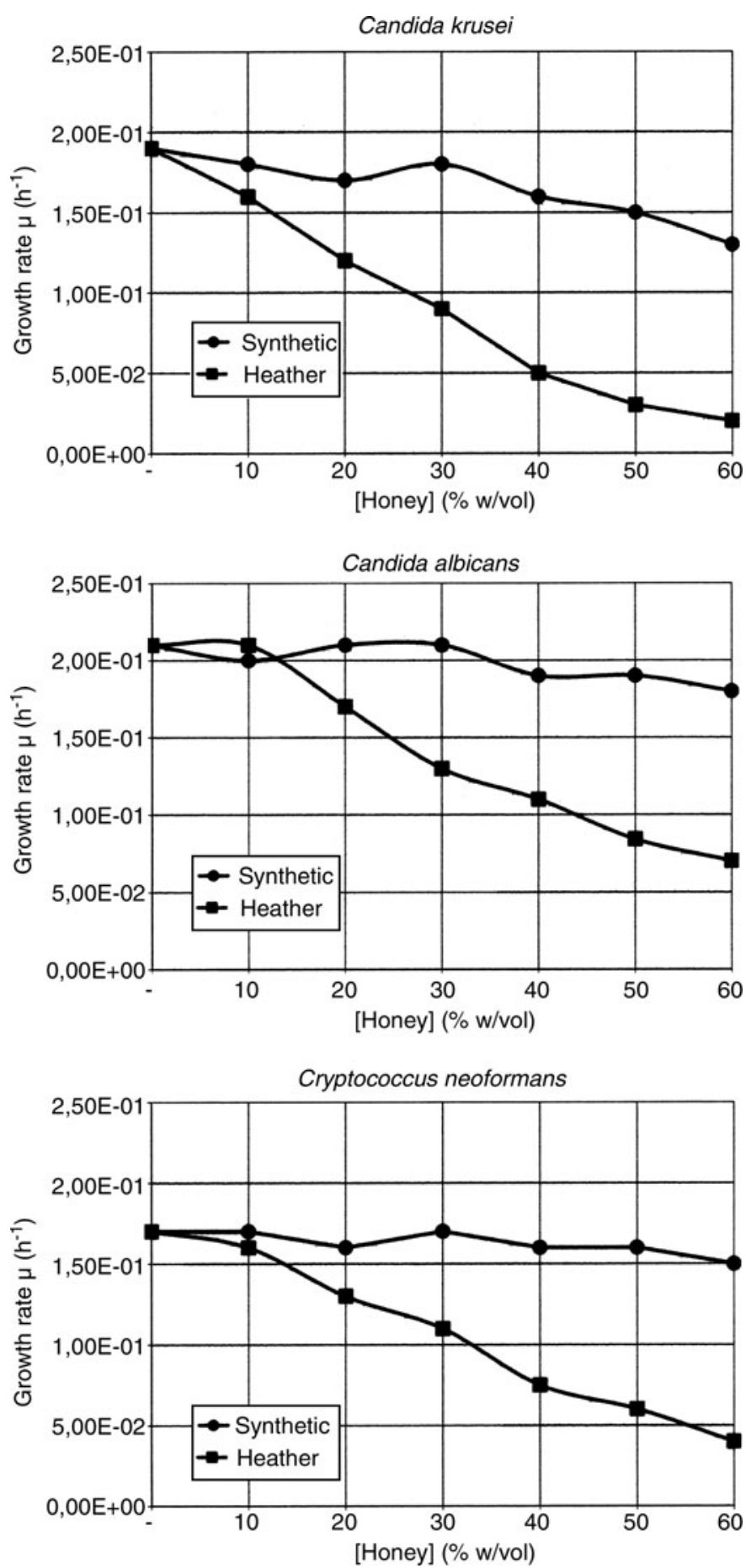

FIG. 1. Fungal growth rate $\left(\mu\right.$, in $\left.\mathrm{h}^{-1}\right)$ in the presence of heather honey and synthetic honey at different concentrations (wt/vol).

verified in the presence of wasbessie honey at concentrations of $25 \% .^{4}$ The minimum inhibitory concentration of honeys against isolates of Candida species (C. albicans, Candida glabrata, and Candida dubliniensis) would be achievable in a clinical setting, ${ }^{5}$ with $C$. dubliniensis being more susceptible to the osmotic effect of all honeys and to the antifungal effects of Jarrah honey. However, in contrast,
Table 1. Heather Honey and Synthetic Honey Concentrations That Inhibited 10\% and 90\% of YeAst Growth

\begin{tabular}{lccccc}
\hline \multirow{2}{*}{ Yeast } & \multicolumn{4}{c}{ Concentration $(\%, w t / v o l)$} \\
\cline { 2 - 3 } \cline { 5 - 6 } \cline { 5 - 6 } C. albicans & \multicolumn{2}{c}{ Heather honey } & & \multicolumn{2}{c}{ Synthetic honey } \\
\cline { 2 - 3 } C. krusei & $X_{\min }$ & $X_{\max }$ & & $X_{\min }$ & $X_{\max }$ \\
C. neoformans & 13.5 & $>60.0$ & & $>60.0$ & - \\
\hline
\end{tabular}

$X_{\min }$ and $X_{\max }$ represent concentrations that inhibited $10 \%$ and $90 \%$, respectively, of yeast growth.

previous studies with different types of honey, tested at several concentrations ranging from $0.1 \%$ to $20 \%{ }^{2}$ and from 25 to $100 \%,{ }^{25}$ revealed that the growth of $C$. albicans was not inhibited by the honeys.

Several factors may influence the antifungal activity of honey. These factors include its physicochemical properties, botanical origin, entomological origin, and symbioses with beneficial bacteria. The literature reviewed shows us that research on monofloral Erica sp. honeys is mainly focused on their physicochemical and palynological features, ${ }^{26-29}$ the assessment of the possible markers for their floral origin, ${ }^{30}$ the development of an electronic tongue for heather honey classification, ${ }^{31}$ and, more recently, the antioxidant and antibacterial properties of the phenolic compounds found in Portuguese heather honey, demonstrated with promising results. $^{32}$

The healing properties of honey depend largely on the floral source that nourishes the honeybees. For example, DeMera and Angert ${ }^{33}$ reported that honeys from different phytogeographic regions varied in their ability to inhibit the growth of yeasts, suggesting that botanical origin plays an important role in influencing the antifungal activity. Erica sp. contain many active substances such as flavonoids, anthocyanidols, coumarins, and triterpenic compounds, which are expected to be found in heather honey. Moreover, major compounds of Erica sp. flowers have been isolated and proved to have antimicrobial ${ }^{34}$ and antiulcer ${ }^{35}$ activities as well as cytotoxic and anticarcinogenic properties. ${ }^{36}$ Analysis of phenolic compounds in heather honey samples showed that about 14 phenolic compounds could be identified (five flavonoids and nine phenolic acids) and that the phenolic pattern of honey contains protocatechic acid, $p$ hydroxybenzoic acid, caffeic acid, chlorogenic acid, vanillic acid, p-coumaric acid, benzoic acid, chrysin, and cinnamic acid, as well as the flavonoids naringenin, kaempferol, apigenin, pinocembrin, and ellagic acid. ${ }^{37}$ In plants, ellagic acid is present in the form of ellagitannin, which is ellagic acid bound to a sugar molecule. Ellagitannins are hydrolyzed by bee enzymes to yield ellagic acid, the bioactive agent that offers protection. Although recent work shows that there are other compounds present, which could not be identified because of lack of availability of standard compounds, ${ }^{32}$ it has been concluded that ellagic acid and 
myricetin-30-methylether (which have not been identifying in any of the monofloral honeys investigated so far) seem to be potential markers for the floral origin of heather honey. ${ }^{32,38,39}$ Therefore, different honey properties were expected because the composition of active compounds in honey from different locations should be different.

In conclusion, the antifungal effect of organic heather honey was evaluated in culture medium containing different concentrations of honey. What the data suggest is that the component in the heather honey responsible for the observed antifungal in vitro properties is not sugar based. Although the therapeutic action of honey has been given some attention by researchers, studies have only been done by screening raw honey samples. The use of novel and powerful high-throughput techniques that currently are used in drug development will be of value to ascertain the medical properties of honey. Once the compound's structure is known, the chemical can serve as a prototype or "lead compound" for designing more effective therapeutic agents of similar chemical structure.

\section{ACKNOWLEDGMENTS}

We would like to thank the Portuguese beekeepers who kindly supplied us with the honeys for this study. We sincerely thank to Prof. Teresa Sánchez, for critically reading the manuscript and making a number of helpful suggestions.

\section{AUTHOR DISCLOSURE STATEMENT}

No competing financial interests exist.

\section{REFERENCES}

1. Molan P: Why honey is effective as a medicine. Bee World 2001;82:22-40.

2. Lusby PE, Coombes AL, Wilkinson JM: Bactericidal activity of different honeys against pathogenic bacteria. Arch Med Res 2005;36:464-467.

3. Bardy J, Slevin NJ, Mais KL, Molassiotis A: A systematic review of honey uses and its potential value within oncology care. J Clin Nurs 2008;17:2604-2623.

4. Theunissen F, Grobler S, Gedalia I: The antifungal action of three South African honeys on Candida albicans. Apidologie 2001:32:371-379.

5. Irish J, Carter DA, Shokohi T, Blair S: Honey has an antifungal effect against Candida species. Med Mycol 2006;44:289-291.

6. Küçük M, Kolailı S, Karaoğlu Ş, Ulusoy E, Baltacı C, Candan F: Biological activities and chemical composition of three honeys of different types from Anatolia. Food Chem 2007;100:526-534.

7. Boukraa L, Benbarek H, Moussa A: Synergistic action of starch and honey against Candida albicans in correlation with diastase number. Braz, J Microbiol 2008;39:40-43.

8. Koc AN, Silici S, Kasap F, Hörmet-Oz HT, Mavus-Buldu H: Antifungal activity of Turkish honey against Candida spp. and Trichosporon spp: an in vitro evaluation. Med Mycol 2008;2:1-6.

9. Bogdanov S, Jurendic T, Sieber R, Gallmann P: Honey for nutrition and health: a review. J Am Coll Nutr 2008;27:677-689.

10. Tucak Z, Periskić M, Beslo D, Tucak I: Influence of the beehive type on the quality of honey. Coll Antropol 2004;28:463-467.
11. Rial-Otero R, Gaspar EM, Moura I, Capelo JL: Chromatographic-based methods for pesticide determination in honey: an overview. Talanta 2007;71:503-514.

12. European Union: Council Directive 834/2007 on organic production and labelling of organic products. Off J Eur Commun 2007;L189:1-23.

13. Fridkin SK: The changing face of fungal infections in health care settings. Clin Infect Dis 2005;41:1455-1460.

14. Pappas PG, Rex JH, Lee J, et al.: A prospective observational study of candidemia: epidemiology, therapy, and influences on mortality in hospitalized adult and pediatric patients. Clin Infect Dis 2003;37:634-643.

15. Tortorano AM, Kibbler C, Peman J, Bernhardt H, Klingspor L, Grillot R: Candidaemia in Europe: epidemiology and resistance. Int J Antimicrob Agents 2006;27:359-366.

16. Nguyen KT, Ta P, Hoang BT, et al.: Characterising the postantifungal effects of micafungin against Candida albicans, Candida glabrata, Candida parapsilosis and Candida krusei isolates. Int J Antimicrob Agents 2010;35:80-84.

17. Perfect JR, Casadevall A: Cryptococcosis. Infect Dis Clin North Am 2002;16:837-874.

18. European Union: Council Directive 509/2006 on agricultural products and foodstuffs as traditional specialities guaranteed. Off J Eur Commun 2006;L93:1-11.

19. Harfani H, Bouanani N, Aziz M, Caid H, Ghalim N, Amrani S: The hypolipidaemic activity of aqueous Erica multiflora flowers extract in Triton WR-1339 induced hyperlipidaemic rats: a comparison with fenofibrate. J Ethnopharmacol 2007;109:156-160.

20. Akkol E, Yeşilada E, Güvenç A: Valuation of anti-inflammatory and antinociceptive activities of Erica species native to Turkey. $J$ Ethnopharmacol 2007;116:251-257.

21. Tuzlaci E, Aymaz EP: Turkish folk medicinal plants, Part IV: Gönen (Balikesir). Fitoterapia 2001;72:323-343.

22. Pires J, Estevinho ML, Feás X, Cantalapiedra J, Iglesias A: Pollen spectrum and physico-chemical attributes of heather (Erica sp.) honeys of north Portugal. J Sci Food Agric 2009;89: 1862-1870.

23. Becker JM, Caldwell GA, Zachgo EA: Sterilization Methods. In: Biotechnology: A Laboratory Course, $2^{\text {nd }}$ ed. Academic Press, San Diego, CA, 1996.

24. Calhelha RC, Andrade JV, Ferreira IC, Esteviño LM: Toxicity effects of fungicide residues on the wine-producing process. Food Microbiol 2006;23:393-398.

25. Omafuvbe BO, Akanbi OO: Microbiological and physicochemical properties of some commercial Nigerian honey. Afr J Microbiol Res 2009;3:891-896.

26. Silva LR, Romeu V, Monteiro AP, Valentão P, Andrade PB: Honey from Luso region (Portugal): physicochemical characteristics and mineral contents. Microchem J 2009;93:73-77.

27. Andrade PB, Amaral MT, Isabel P, Carvalho J, Seabra R, Cunha A: Physicochemical attributes and pollen spectrum of Portuguese heather honeys. Food Chem 1999;66:503-510.

28. Nozal MJ, Bernal JL, Diego JC, Martin MT: Classifying honeys from the Soria Province of Spain via multivariate analysis. Anal Bioanal Chem 2005;382:311-319.

29. Persano-Oddo L, Piro R: Main European unifloral honeys: descriptive sheets. Apidologie 2004;35(Suppl 1):S38-S81.

30. Ferreres F, Andrade P, Gil MI, Tomás-Barberán FA: Floral nectar phenolics as biochemical markers for the botanical origin of heather honey. Z Lebensm Unters F A 1996;202:40-44. 
31. Dias LA, Peres AM, Vilas-Boas M, Rocha MA, Estevinho L, Machado AASC: An electronic tongue for honey classification. Microchim Acta 2008;163:97-102.

32. Estevinho L, Pereira AP, Moreira L, Dias LG, Pereira E: Antioxidant and antimicrobial effects of phenolic compounds extracts of Northeast Portugal honey. Food Chem Toxicol 2008;46:3774 3779.

33. DeMera JH, Angert ER: Comparison of the antimicrobial activity of honey produced by Tetragonisca angustula (Meliponinae) and Apis mellifera from different phytogeographic regions of Costa Rica. Apidologie 2004;35:411-417.

34. Toro MV, García MD, Pascual M: Isolement et identification des acides phénols chez Erica andevalensis Cabezudo-Ribera: leur contribution à l'activité antimicrobienne de l'espèce. Ann Pharm Fr 1987;45:401-407.
35. Reyes M, Martín-Cordero C, Ayuso MJ, Toro MV, Alarcon de la Lastra C: Antiulcer activity in rats by flavonoids of Erica andevalensis Cabezudo-Rivera. Phytother Res 1996;10:300-303.

36. Güvenç A, Kendir G, Eken A: Evaluation of inorganic compounds of Erica L. species (Ericaceae) native to Turkey. FABAD J Pharm Sci 2007;32:121-125.

37. Anklam E: A review of the analytical methods to determine the geographical and botanical origin of honey. Food Chem 1998;63: 549-562.

38. Andrade P, Ferreres F, Amaral MT: Analyses of honey phenolic acids by HPLC, its application to honey botanical characterization. J Liq Chromatogr Relat Technol 1997;20:2281-2288.

39. Andrade P, Ferreres F, Gil MI, Tomás-Barberán FA: Determination of phenolic compounds in honeys with different floral origin by capillary zone electrophoresis. Food Chem 1997;60: 79-84. 
JMF-2010-0211-ver9-Feas_1P.3d 04/21/11 12:12pm Page 6

\section{AUTHOR QUERY FOR JMF-2010-0211-VER9-FEAS_1P}

AU1: Give inclusive pages for this chapter. 